\title{
Globalização e Poder de Estado: Circulação Internacional de Elites e Hierarquias do Campo Jurídico Brasileiro*
}

\section{Fabiano Engelmann}

Professor do Departamento de Ciência Política e do Programa de Pós-Graduação em Ciência Política da Universidade Federal do Rio Grande do Sul (UFRGS). E-mail:

fabengel@gmail.com.

\begin{abstract}
A ascensão de agentes portadores de maior capital internacional no $A$ espaço do poder político e econômico tem sido destacada por estudos que enfocam o perfil e os recursos mobilizados pelos grupos dirigentes, especialmente nos países periféricos ${ }^{1}$. A formação acadêmica no exterior e a inserção em redes internacionais de comércio, de militância política e de cooperação científica contribuem para a emergência ou o reforço de posições de poder no âmbito nacional.

A repercussão no espaço doméstico das diversas espécies de capital internacional mobilizadas pelas elites políticas, burocráticas e acadêmicas está diretamente relacionada a outras modalidades de recursos, dentre os quais podemos destacar: o capital escolar, o capital familiar e os trunfos acumulados em trajetos profissionais anteriores e combinados com a "passagem internacional". Logo, uma das possibilidades de apreender a importância adquirida por essa forma de recurso é verificar sua presença nos trajetos dos agentes que ocupam posições de elite em um campo social determinado.
\end{abstract}

\footnotetext{
* Este artigo resulta do projeto de pesquisa Globalização e Rule of Law: as disputas em torno do sentido político do sistema judicial brasileiro que contou com apoio do Conselho Nacional de Desenvolvimento Científico e Tecnológico (CNPq). Agradeço as sugestões apresentadas pelos pareceristas anônimos da DADOS que contribuíram muito para o enriquecimento da versão final.
}

DADOS - Revista de Ciências Sociais, Rio de Janeiro, vol. 55, n-2, 2012, pp. 487 a 516. 
O presente artigo pretende discutir a relevância do capital internacional na hierarquização de um segmento específico tradicionalmente detentor de grande fatia do poder de Estado: os juristas. Ao estudar seus percursos e a relação com as expertises jurídicas, tem-se uma porta aberta para investigar a reconfiguração do poder de Estado. Como assinala Abel (1998), o Estado age através do Direito e, consequentemente, pode ter sua autoridade direcionada por sentidos do Direito que prevalecem em determinados contextos.

\section{"GLOBALIZAÇÃO POLÍTICA", CAPITAL INTERNACIONAL E RECOMPOSIÇÃO DO CAMPO DO PODER}

O fenômeno da produção e difusão de expertises sobre o Estado - bem como os efeitos de resistência às "prescrições globais" - pode ser estudado a partir do grau de investimento das diversas configurações de elites no espaço internacional. Nesse sentido, a "globalização política" é abordada como um prolongamento das "guerras palacianas", nas quais as batalhas em torno de definições de modelos institucionais são vinculadas à disputa dos diversos grupos dirigentes pelo poder político em um espaço crescentemente internacionalizado.

Conforme a definição de Bourdieu (1989), as "guerras palacianas" implicam não apenas disputas pelo controle do Estado, mas também definições legítimas das instituições. Logo, para a compreensão das "prescrições globais", a análise do "conhecimento científico" a respeito dos modelos institucionais e das condições de sua apropriação são dimensões fundamentais no estudo do acesso de indivíduos e grupos ao espaço decisório.

Pode-se afirmar que o grau de internacionalização de um campo específico é diretamente proporcional à variação da relevância do capital internacional na trajetória dos grupos dirigentes. Esta espécie de capital pode ser definida como o conjunto de recursos detidos por grupos e indivíduos, certificado em títulos acadêmicos, honoríficos ou derivado de contatos e relações estabelecidas com elites e instituições estrangeiras.

Quando se pauta como objeto a relação entre dinâmicas centrais na produção de conhecimento e países que podem ser considerados periféricos, a circulação internacional das elites e sua afirmação como mediadora de formatos institucionais assumem um papel-chave. Os bens simbólicos importados são redefinidos pelas diversas estratégias enta- 
buladas nas disputas entre os segmentos da elite política e intelectual, tal como referem Badie e Hermet (1990) e Badie (1992), ao examinarem o longo processo de "ocidentalização da ordem política" em contextos periféricos.

A análise da diversidade das condições de legitimação do capital internacional acumulado por elites cosmopolitas também contribui para evitar-se uma associação mecânica entre a "globalização" e a formação dos grupos dirigentes e especialidades acadêmicas. Ou seja, em determinados espaços, frações mais cosmopolitas das elites não se superpõem necessariamente a camadas com menor capital internacional com condições de movimentar recursos derivados de relações sociais, educacionais, políticas e profissionais ancoradas localmente. Essa variedade de mecanismos mobilizados corresponde às diversas disputas pelo sentido das instituições e princípios que permeiam as esferas políticas.

O reconhecimento do modelo americano de gestão do Estado e da macroeconomia na América Latina nas décadas de 1980 e 1990 pode ser relacionado à disputa entre elites pelo controle de recursos estatais e do saber legítimo sobre a gestão pública, em especial entre juristas que mobilizam uma tradição humanística e economistas relacionados a um saber-fazer econômico calcado na modelização matemática ${ }^{2}$.

Em grande medida, a legitimação internacional do modelo americano de gestão passa pela obtenção - por think-thanks ${ }^{3}$ - de posições no âmbito de universidades, fundações de financiamento de pesquisa e agências financeiras nacionais de fomento, como o Banco Mundial e o Fundo Monetário Internacional (FMI). Assim, sedimentam-se internacionalmente modelos relacionados à história específica do desenvolvimento das multinacionais americanas, como analisa Dezalay (2004).

No caso do Brasil, um conjunto de trabalhos que tem por foco a circulação internacional de elites ${ }^{4}$ e o intercâmbio universitário mostra a importância das estratégias internacionais na recomposição dos grupos dirigentes e o espaço universitário como lócus de redefinições do sentido das instituições.

No que concerne aos cientistas políticos, Forjaz (1997) e Canedo (2009) indicam a ação da Fundação Ford através da concessão de bolsas de estudo para a formação da primeira geração de acadêmicos brasileiros, recrutada majoritariamente entre alunos da Universidade Federal de 
Minas Gerais (UFMG) e com formação de pós-graduação em universidades americanas. O grupo que construiu o espaço da ciência política no âmbito das ciências sociais brasileiras foi fundamental para a ligação com centros acadêmicos americanos e para a recepção de modelos de ciência política no Brasil. Em especial, evidenciou-se a batalha no âmbito das ciências sociais pela abordagem da "política como variável autônoma", bem como fundamentou a formação de outras gerações vinculadas a diversas agências americanas. O processo de legitimação desse grupo e da autonomia disciplinar da ciência política envolveu a disputa com grupos acadêmicos já constituídos que detinham o monopólio do estudo das instituições brasileiras, como os bacharéis em Direito e os sociólogos ligados, por exemplo, à Universidade de São Paulo (USP).

Com maior êxito do que os cientistas políticos ao elaborarem espaços no interior de arenas decisórias, os economistas, como indica Loureiro (1997), legitimaram-se na construção do monopólio da formulação e condução de políticas macroeconômicas no Brasil ao longo da década de 1970. A intensificação da formação em universidades americanas coadunou-se com o deslocamento dos modelos de cultura econômica e seus representantes, vinculados a uma geração desenvolvimentista pelo grupo formado na linha monetarista. Esta última, ao ascender a posições-chave nos ministérios que definem as políticas macroeconômicas na década de 1990, contribuiu para a recepção no Brasil dos modelos das agências de ajuda ao desenvolvimento e para a propagação das teses do ajuste das economias na América Latina.

Pode-se mencionar também, como caso representativo da estreita relação entre a formação estrangeira e a recomposição de expertises no espaço doméstico, a formação mais recente dos especialistas em Administração. Os conhecimentos em administração e gestão são permeados por processos de diversificação e recomposição homólogos à expansão das empresas brasileiras que, ao longo da década de 1990 e em função dos processos de abertura da competição econômica internacional, passam a se adequar com maior velocidade às regras de competição. A passagem dos executivos por Master Business of Administration (MBAs) nos Estados Unidos torna-se obrigatória, assim como para profissionais oriundos de outras especialidades disciplinares, que se reconvertem a "gestão" e se afinam com a recomposição das organizações empresarias e dos perfis dos patrons brasileiros (Grün, 2004; López-Ruiz, 2007). 
Nesse contexto geral, de estreitamento da relação entre formação de vínculos internacionais, absorção de modelos e conquista de espaços de poder no âmbito doméstico, pode-se perguntar como fica o caso dos juristas, cujo poder é fortemente ancorado na força do Estado nacional.

\section{CAPITAL INTERNACIONAL DOS JURISTAS E HIERARQUIZAÇÃO DO CAMPO JURÍDICO}

Em trabalho sobre a América Latina, Dezalay e Garth (2002) enfocam o papel da circulação internacional das tecnologias institucionais e das definições do Direito, em que se firmam um polo produtor (Europa e, mais recentemente, Estados Unidos) e um polo importador (Brasil e América Latina). Esse fluxo de modelos e problemáticas envolve sua assimilação e uso para a legitimação de determinados grupos dirigentes nacionais. Uma das dimensões mais evidentes desse fenômeno, conforme Dezalay e Garth (ibidem), são as estadas acadêmicas em países centrais, que proporcionam a acumulação de capital internacional e que, em muitos casos, projetam grupos como intermediários na exportação de modelos e tecnologias dos países centrais para os periféri$\cos$.

Para uma melhor verificação da hipótese dos autores quanto à circulação dos juristas brasileiros e à reconversão das modalidades de capital internacional acumulado em posições de poder doméstico, há necessidade de incluir indicadores que apontem maior detalhamento das relações estabelecidas entre os importadores e sua validade em campos específicos. Essas estratégias de importação podem envolver tanto a reconversão de setores tradicionais, mas com posições sociais ameaçadas, quanto a legitimação de novos grupos de juristas.

A definição de campo jurídico desenvolvida por Bourdieu (1986) atenta para o estudo da relação entre os recursos acumulados pelos agentes e as posições e os sentidos atribuídos às suas práticas. Conforme Bourdieu (ibidem), este campo funciona a partir da concorrência entre os agentes que definem o sentido da justiça e o conhecimento jurídico construído na forma de doutrinas:

As práticas e os discursos jurídicos são, com efeito, o produto do funcionamento de um campo cuja lógica específica está duplamente determinada: por um lado, pelas relações de força específicas que lhe conferem a sua estrutura e que orientam as lutas de concorrência, ou mais precisamente, os conflitos de competência que nele têm lugar e, por ou- 
tro lado, pela lógica interna das obras jurídicas que delimitam em cada momento o espaço dos possíveis e, deste modo, o universo das soluções propriamente jurídicas (Bourdieu, 1986:3-4).

No Brasil, a tradição de escolas de pensamento, a produção doutrinária e a legitimidade política do monopólio de enunciar a justiça desde o Império $^{5}$ estão diretamente relacionadas à posição ocupada (permanente ou passageira) no âmbito do Estado e com os vínculos mantidos com a matriz europeia de sistema jurídico. Entretanto, a emergência de setores especializados em produção intelectual - como o ensino de pós-graduação e a expansão de grandes sociedades de advogados - introduz novas categorias de atores, ampliando a batalha simbólica que cerca o espaço da justiça. Destaca-se a crescente concorrência de institutos típicos do Direito anglo-americano, particularmente no domínio da regulação econômica e nas práticas de arbitragem comercial.

No caso do campo jurídico, os efeitos da internacionalização - tanto no sentido da redefinição das instituições judiciais, quanto no aumento da relevância do capital internacional na sua hierarquização demandam estudos mais aprofundados. Nesse sentido, pretende-se, através da exposição de uma análise de percursos dos ocupantes de posições de destaque nesta área, propor questões de pesquisa sobre essa temática.

\section{NOTA SOBRE A CONSTRUÇÃO DOS DADOS DA PESQUISA}

Consideraram-se para a construção da pesquisa, três grandes dimensões do campo jurídico brasileiro: o espaço acadêmico, o espaço do poder judicial e o espaço da advocacia.

A inclusão do espaço acadêmico justifica-se pela crescente importância e exponencial aumento da titulação acadêmica de pós-graduação em Direito e pelo fenômeno da profissionalização deste espaço a partir da segunda metade da década de 1990 (Engelmann, 2006). Assim, nota-se que aqueles que concentram maior número de atributos propriamente acadêmicos (titulação de doutorado, publicações em revistas acadêmicas, circulação internacional, entre outros que são fundamentais para a ocupação da posição de docente em pós-graduação) representam um grupo relativamente pequeno em relação ao conjunto dos professores posicionados no ensino de graduação e com titulação e atributos acadêmicos menores ${ }^{6}$. 
O espaço judicial é composto por todos aqueles que exercem a função da magistratura e outras carreiras jurídicas de Estado, incluindo também a advocacia. Tendo em vista a hierarquização institucional do poder Judiciário, pode-se afirmar que uma das principais posições de elite é dada pela ocupação de postos de ministros em tribunais superiores. Dentre estes, optou-se por enfocar como representativos os ministros do Supremo Tribunal Federal (STF) e do Superior Tribunal de Justiça (STJ) - posicionados nas duas mais importantes cortes - considerando a diversidade de matérias e a repercussão pública das decisões. Neste caso, a posição na elite jurídica é assegurada, principalmente, pelos recursos institucionais de exercício de um poder de Estado que estes indivíduos concentram.

Finalmente, a inclusão do espaço dos advogados justifica-se pelo conjunto de estudos ${ }^{7}$ que evidenciam o crescimento de um modelo de advocacia no Brasil, relativamente próximo ao das grandes firmas americanas. Conforme esses trabalhos, o crescimento de escritórios de advocacia com um grande número de sócios, sedes no exterior e vinculados à representação de interesses de empresas multinacionais gera impacto na redefinição do mercado advocatício no Brasil. Dessa forma, os principais sócios posicionados nessas sociedades, podem ser tomados como representativos da elite da advocacia, em relação a escritórios menores com atuação local e com menor presença no mercado internacional.

Para fins de operacionalização da pesquisa, a exploração dos trajetos profissionais e acadêmicos apresentada neste texto resulta de três polos da elite jurídica brasileira: (1) os professores de Direito atuando nos cursos de pós-graduação entre 2006 e 2007; (2) os advogados membros das sociedades de advogados brasileiras; e (3) os ministros do STJ e do STF atuando entre 2007 e 2008.

A pesquisa parte de uma primeira fase predominantemente objetivista. Busca-se - através da comparação sistemática das trajetórias universitárias, profissionais, políticas e informações biográficas gerais identificar padrões de recursos e indicativos dos princípios de estruturação da ascensão à cúpula do espaço jurídico dos segmentos estudados. Uma segunda fase centra-se na análise qualitativa da produção intelectual e nas tomadas de posição pública dos agentes, tendo por foco a relação dessa dimensão perspectivista com os dados construídos e apreendidos na primeira parte. Os dados que subsidiam o presente ar- 
tigo não são apresentados de forma linear em função da disparidade e limitações das fontes utilizadas.

Para os professores universitários, foi realizada uma coleta de informações na plataforma Lattes, do CNPq, no segundo semestre de 2006 e no início de 2007. Foram pesquisados os currículos de todos os professores registrados em pós-graduações stricto sensu em universidades brasileiras. O total chegou a 650 casos (grandeza aproximada), visto que diversos contêm informações incompletas, múltipla inserção em programas ou discrepâncias entre a listagem de professores fornecida no site da Coordenação de Aperfeiçoamento de Pessoal de Nível Superior (Capes) e os dados da plataforma. Do número analisado, chegou-se a 123 casos que apresentaram alguma modalidade de estudo no exterior declarada no currículo, para os quais foram construídos os dados.

Para os advogados, foi utilizado, principalmente, o Anuário Análise Advocacia 2007, que contém um ranking e um perfil das 474 maiores sociedades de advogados do Brasil. Este anuário é uma publicação com fins jornalísticos e fornece também um perfil dos sócios dos escritórios. Entretanto, não contém informações homogêneas e completas para toda a população. Foram usadas fontes complementares, como a consulta ao site do Centro de Estudos das Sociedades de Advogados (CESA) e à revista Advogados-Mercados e Negócios do número 1-2005 ao número 8/ ano 2-2006.

Para os ministros do STF e STJ, foram consultadas as publicações Análise Justiça de 2007 e a publicação Anuário da Justiça de 2008 e 2009. As obras contêm dados biográficos relativamente homogêneos e perfis de decisões judiciais a respeito de temas considerados jornalisticamente de "maior repercussão" ao longo do ano.

Para a construção dos dados sobre os percursos dos segmentos analisados, foram feitos quadros comparativos com as seguintes categorias: (1) formação acadêmica (títulos universitários nacionais); (2) formação no exterior (títulos universitários e escolares); (3) domínio de idioma estrangeiro; (4) carreira profissional e política (ocupações, postos públicos ocupados, exercício de mandatos); e (5) informações indicativas de participações de ocupação de postos políticos ou em entidades. A comparação desses percursos permitiu relacioná-los às posições ocupadas e fornecer indicações sobre os recursos mobilizados pelos agentes pesquisados. 


\section{OS PROFESSORES E A EXPANSÃO DO CONHECIMENTO ACADÊMICO SOBRE 0 DIREITO}

As condições de profissionalização e autonomização da carreira dos docentes no ensino jurídico até a década de 1990 eram raras. O exercício da docência representou historicamente uma honraria para os "bons práticos" ou "grandes juristas", como apontam os trabalhos de Adorno (1988) sobre a Academia do Largo de São Francisco e Venâncio Filho (1977) sobre a história do ensino jurídico no Brasil, incluindo o período republicano. Na maioria dos casos, uma forma complementar de renda ou acúmulo de prestígio para detentores de postos no Judiciário ou de escritórios de advocacia.

A profissionalização na atividade docente iniciou-se com mais força a partir da década de 1990, no contexto de mudança nas exigências de reconhecimento dos cursos jurídicos por parte do Ministério da Educação e de expansão do ensino privado de graduação e pós-graduação. Tais efeitos de conjuntura propiciaram a valorização dos títulos universitários e a aposta de diversos bacharéis em Direito na dedicação ao ensino como atividade principal ${ }^{8}$. A emergência da docência e o crescimento dos programas de pós-graduação acompanharam a recomposição e o aumento do poder judicial, além da legitimação do monopólio dos juristas como "guardiões da Constituição" e das diversas "questões sociais" formalizadas no contexto da redemocratização.

A ampliação da população com titulação de doutorado e ocupante da posição de professor integral em cursos de pós-graduação levou a uma maior valorização da qualificação no exterior. O uso da titulação de doutorado e dos contatos acadêmicos obtidos em outros países, aliado à apreensão e domínio das regras do jogo institucional das instâncias reguladoras, projetou grupos de docentes para o topo da carreira acadêmica.

O predomínio de estadas nos países europeus e a formação majoritariamente vinculada ao Direito Público, entretanto, indicam a estreita vinculação do campo acadêmico do Direito com as demandas das práticas judiciais advindas do contexto da redemocratização no Brasil. Ou seja, a redefinição das funções de Estado e a expansão do poder político da magistratura e de outras carreiras jurídicas afinaram-se à legitimação dos produtos acadêmicos e à expansão massiva de programas de pós-graduação em Direito Público. 
São importantes as indicações que mostram que diversos "juristaspráticos" investem em titulação acadêmica de pós-graduação e mantêm uma carreira híbrida, posicionando-se simultaneamente na cúpula do ensino universitário e nas carreiras de Estado. A análise do perfil dos estudos no exterior e dos trajetos profissionais dos docentes contribui para melhor apreensão da natureza do capital internacional acumulado por esse segmento.

O estabelecimento de uma cronologia a partir da data de conclusão dos estudos no exterior permite indicações relevantes. Entre os casos analisados, o mais antigo concluiu curso no exterior em 1950 e o mais recente, em 2006. É no intervalo entre 1996-2006 que se concentra o maior número de docentes com passagem pelo exterior. Predominam os países da Europa - Itália, Alemanha, Portugal, Espanha e França - como os mais procurados. Os Estados Unidos aparecem em oito casos e o Canadá em dois casos. A escolha desses países pode ser contrastada ao caso dos advogados fundadores dos maiores escritórios, majoritariamente sem atuação acadêmica. Eles realizam estudos no exterior, predominantemente nos Estados Unidos, e com apoio financeiro familiar ou mesmo das sociedades de advogados às quais se vinculam.

Observa-se, entre os docentes, que as estadas sem bolsa se concentram na Espanha, Itália e Portugal - os países mais procurados nesse intervalo. Dos 17 casos que não declaram ter bolsa, dez têm cargo público de magistrado ou procurador. Entre os docentes que partem para o exterior, a maioria realiza doutorado, título de entrada para a ascensão à cúpula da carreira acadêmica que, no caso do ensino jurídico, assume grande peso em função de sua maior raridade no universo mais amplo de docentes.

Há grande diversidade dos temas de estudo com predomínio do "direito internacional". Temas de "filosofia do direito", "teoria do direito" e "sociologia do direito" aparecem com frequência maior do que nos períodos anteriores. Os temas mais abstratos e distantes do universo dos práticos, como a filosofia e a sociologia do direito, são mais regulares entre juristas com dedicação exclusiva à carreira acadêmica.

A análise dos países que apresentam maior frequência entre os juristas é uma dimensão importante na apreensão das modalidades de importação de modelos institucionais. Pode-se relacionar a escolha com a inserção no Brasil e a legitimação de seus produtos, assim como o papel de importadores de tecnologias institucionais. As escolhas dos juristas 
Globalização e Poder de Estado: Circulação Internacional de Elites e Hierarquias...

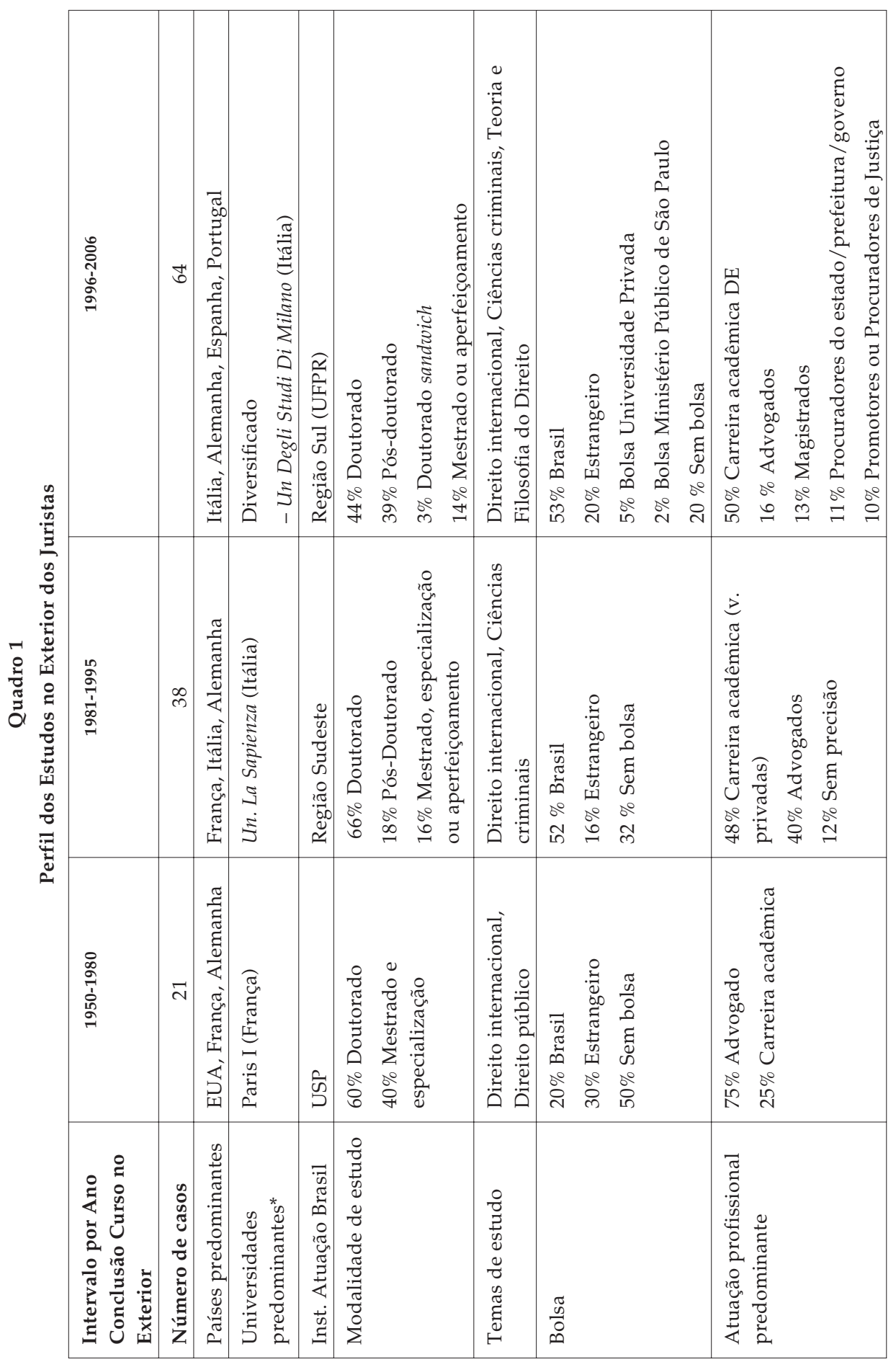

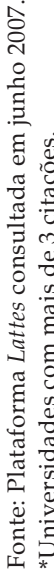


Quadro 2

País de Realização dos Estudos

(Docentes)

\begin{tabular}{|l|c|c|}
\hline País & Frequência & $\%$ \\
\hline França & 27 & 20,9 \\
\hline Itália & 23 & 17,82 \\
\hline Estados Unidos & 21 & 16,27 \\
\hline Alemanha & 19 & 14,72 \\
\hline Espanha & 14 & 10,85 \\
\hline Portugal & 9 & 6,97 \\
\hline Inglaterra & 5 & 3,87 \\
\hline Canadá & 3 & 2,35 \\
\hline Japão & 2 & 1,55 \\
\hline Holanda & 1 & 0,77 \\
\hline Suíça & 1 & 0,77 \\
\hline Bélgica & 1 & 0,77 \\
\hline
\end{tabular}

Fonte: Plataforma Lattes consultada em junho 2007.

opõem-se, no espaço da aquisição de expertises as dos economistas ${ }^{9}$. No caso destes, predominam como polo de formação os Estados Unidos e a Inglaterra, o mesmo ocorrendo para o caso da Administração ${ }^{10}$. Para os juristas, aparecem como polos fundamentais a França, a Itália e a Alemanha, embora não se possa descartar a significativa presença dos Estados Unidos com os incentivos das bolsas Fulbright.

Além da aquisição de expertises, que permitem a "atualização" dos saberes de Estado vinculados ao Direito Público e demandados no contexto da reconstrução do papel político das instituições judiciais no Brasil, a inserção em redes de cooperação acadêmica estrangeiras amplia a ocupação de espaços e a aproximação com segmentos da elite universitária vinculados a outras especialidades.

O bom domínio das regras do jogo institucional e o investimento em uma carreira nova entre juristas favorecem o posicionamento desses agentes na vanguarda da formação de novos programas de mestrado e doutorado, que alimentam o boom do ensino jurídico de pós-graduação a partir da segunda metade da década de 1990. Até 1990, existiam no Brasil, 16 cursos de mestrado em Direito e quatro cursos de doutorado. Em 2006, são 58 cursos de mestrado e 16 cursos de doutorado, representando um exponencial aumento dos produtos intelectuais vol- 
tados ao espaço jurídico, assim como dos postos para os docentes com maior investimento acadêmico.

\section{OS ADVOGADOS DE NEGÓCIOS E O DIREITO A SERVIÇO DA ECONOMIA}

Em um sentido diferente dos usos do capital internacional - acumulado em percursos acadêmicos pelos professores de Direito -, os advogados de negócio têm nas relações internacionais um forte componente de hierarquização. A internacionalização das sociedades de advogados, semelhante aos trajetos de seus sócios, é diretamente proporcional à posição ocupada na advocacia.

Os estudos sobre o espaço profissional evidenciam a relação direta entre a internacionalização das sociedades de advogados e o tamanho destas, indicado pelo número de sócios e amplitude de atuação no mercado. No trabalho de Dezalay (1992), tem-se uma das primeiras pesquisas que destacou o papel das grandes firmas americanas na redefinição dos modelos de advocacia na Europa. A pesquisa mostrou o predomínio dos business-lawyers (vinculados a grandes sociedades de advogados), sobre o modelo tradicional do advogado generalista (chamado pelo autor de gentleman $d u d r o i t)$ e centrado em recursos derivados da sua posição local.

No caso brasileiro, as sociedades de advogados também são hierarquizadas, tendo-se por critério principal o número de sócios. Conforme indicam os trabalhos de Bonelli et alii (2007) e Dezalay e Garth (2002), a relação deste fenômeno com a hierarquização do campo repercute na formação e no recrutamento dos profissionais da advocacia com a valorização de diferentes formas de capital internacional ao longo das décadas de 1990 e 2000. Os dados presentes para as 500 maiores sociedades no Anuário Análise Advocacia 2008 mostram que os escritórios menores - formados por até 20 sócios - possuem abrangência local e baixa presença internacional, tanto na sua atuação, quanto na formação dos sócios.

Os advogados com maior inserção internacional compõem um número relativamente pequeno em relação aos milhares de escritórios de advocacia brasileiros. Localizadas majoritariamente em São Paulo, as grandes sociedades expandiram-se no cenário dos processos de privatização de empresas estatais na década de 1990, o que fica evidenciado no aumento dos números de associados e no quantitativo das que foram fundadas no período. 
As sociedades se diferenciam do modelo tradicional dos pequenos escritórios - individuais ou com até cinco sócios e cuja atuação permanece restrita no âmbito de municípios ou região - conforme indicam os dados presentes nos Anuários Análise Advocacia 2007 e 2008. Considerando os perfis biográficos dos maiores sócios apresentados nos anuários, verifica-se a presença do capital internacional detido na forma de cursos no exterior e habilitações para advogar no estrangeiro, assim como a presença em organismos e associações que evidenciam sua vinculação com o mercado financeiro-corporativo, além do domínio de expertises relacionadas à técnica das operações financeiras e dos negócios.

O perfil das cem maiores sociedades de advogados - definidas a partir do critério do número de sócios - permite detectar forte padrão de internacionalização. Tal fenômeno pode ser medido especialmente por dois fatores inter-relacionados: (1) a realização de cursos de pós-graduação no exterior pelos principais sócios, majoritariamente nos Estados Unidos, nas universidades de Harvard, Columbia, Nova Iorque, Califórnia e Chicago; e (2) a manutenção de sedes e atuação em outros países; especialmente nos Estados Unidos (Miami ou Nova Iorque); e em Portugal (Lisboa). Pode-se mencionar também a existência de acordos com escritórios estrangeiros associados e a relação com redes internacionais de escritórios de negócios como a American Bar Association, International Bar Association, Lex mundi e redes de arbitragem comercial internacional.

A especificidade do espaço das grandes sociedades de advogados aparece na presença de sócios e na especialização na atuação em câmaras nacionais e estaduais de mediação e arbitragem comercial, que representam a configuração de práticas de justiça "fora do Estado". Ainda, a inserção dos advogados em câmaras de comércio-exterior se combina com sua atuação na intermediação de negócios internacionais, que incluem a instalação de empresas estrangeiras e a representação judicial de corporações multinacionais.

Tomando-se as características das vinte maiores firmas de advocacia, definidas pelo número de sócios ${ }^{11}$ (que varia de 125 a 440 advogados), percebe-se que sete entre estas possuem filial no exterior. Três em Nova Iorque, duas em Miami e outras duas em Lisboa. As filiais em Nova Iorque ficam concentradas entre os cinco maiores escritórios, entre os quais, apenas um não possui filial no exterior. A sede majoritária des- 
sas sociedades é São Paulo, em 11 casos; Rio de Janeiro detém sete casos; e Belo Horizonte (MG) e Joinville (SC), um caso cada. Não há uma relação direta entre o tempo de atuação e o tamanho da sociedade, existindo escritórios fundados na década de 1990 que figuram entre os dez maiores.

As atuações predominantes ocorrem nas áreas de "fusões e aquisições", "mercado de capitais" e "direito financeiro e bancário", representando grandes corporações nacionais e internacionais. A atividade registrada no resumo presente no anuário Análise Advocacia 2007 ilustra a participação em fusões milionárias de empresas nacionais e estrangeiras e a presença nos processos de privatização da década de 1990. Os litígios com diversas instituições estatais representando "grandes clientes" são indicativos do poderio dos escritórios. Destacam-se ações que põem diretamente em disputa o sentido de normas regulatórias do mercado financeiro, ou mais amplamente, do direito econômico em ações contra o Banco Central e na representação de clientes envolvidos nos processos de privatização estaduais e nacionais.

A construção do capital internacional dos advogados de negócios tem na passagem por cursos de pós-graduação no exterior um de seus pontos mais importantes. O perfil no anuário Análise Advocacia destaca a fluência em idioma estrangeiro, na maioria dos casos inglês, francês e espanhol. Da mesma forma, é ressaltada a habilitação para advogar em outros países, em especial, Estados Unidos e Portugal. Apesar dos investimentos acadêmicos no exterior, a presença simultânea dos advogados no ensino universitário é ausente entre os principais sócios, o que contrasta com a cúpula do Judiciário.

Em contrapartida, diversos sócios aparecem como diretores ou membros de câmaras de arbitragem, câmaras de comércio exterior e organismos extrajudiciais regulatórios do mercado econômico, como a Comissão de Valores Mobiliários, a Bolsa de Valores de São Paulo e o Conselho Administrativo de Defesa Econômica (CADE). A inserção nesses organismos indica uma espécie de capital político estreitamente vinculado à posição de elite que une a condição de intermediário de negócios com a expertise jurídica. Esse posicionamento dos agentes na fronteira do campo jurídico e econômico permite a legitimação necessária para atuação em instituições que definem regras relacionadas a diversas esferas das relações econômicas. 


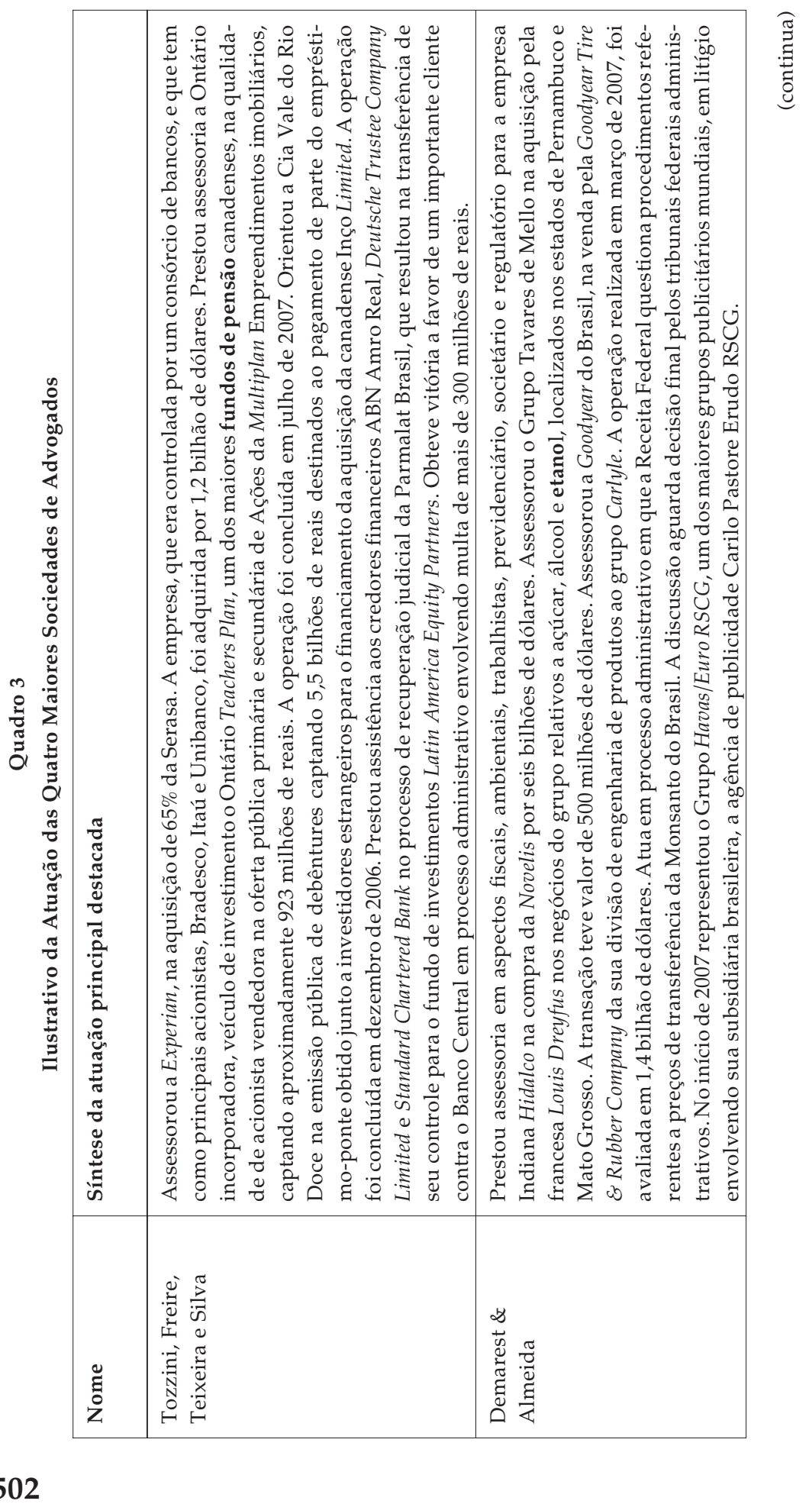


Globalização e Poder de Estado: Circulação Internacional de Elites e Hierarquias...

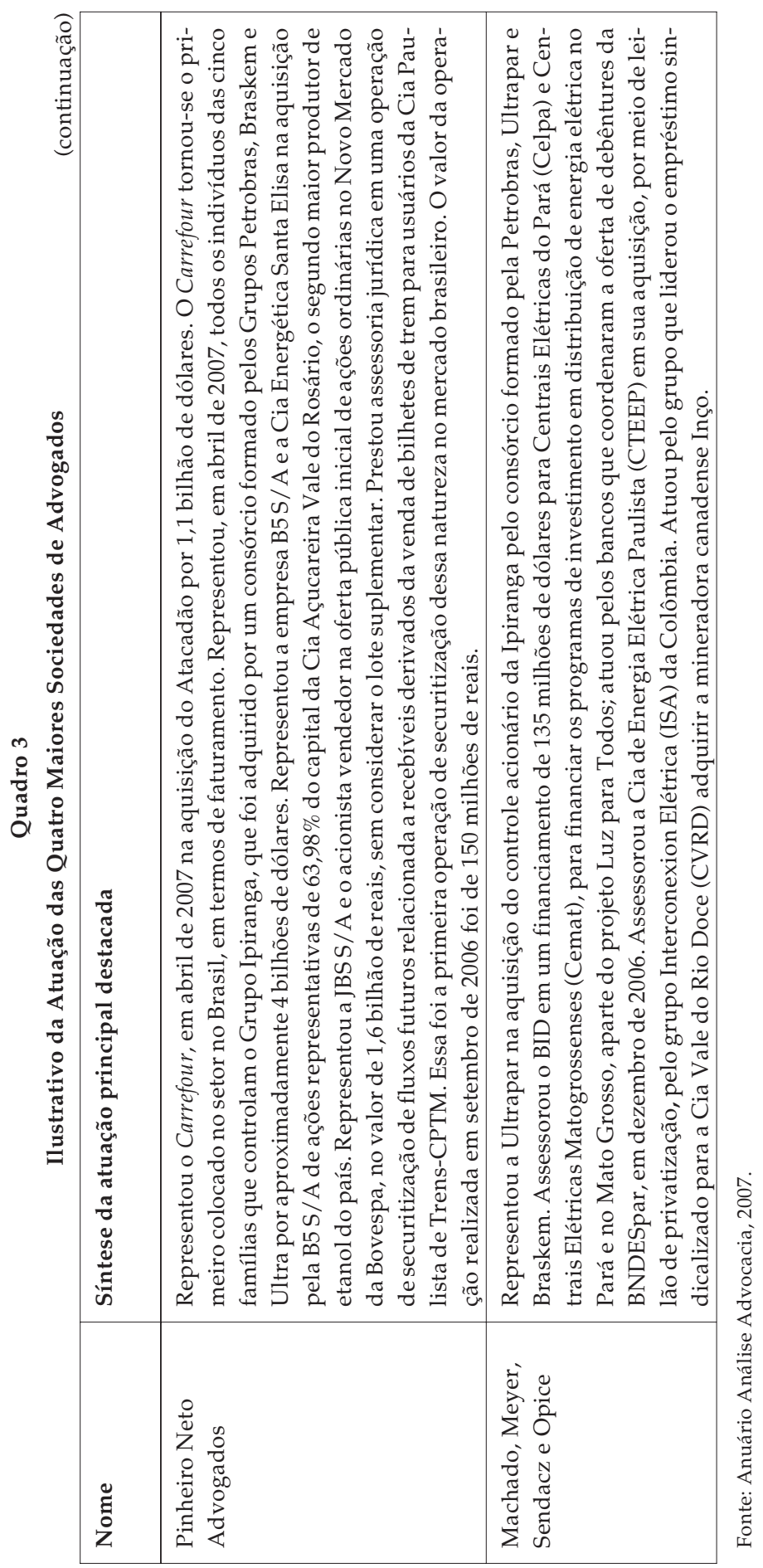


No que concerne ao perfil de carreira profissional dos advogados, apesar da inserção em organismos e conselhos, há uma menor circulação em postos no setor público-estatal. As indicações biográficas também permitem afirmar que se está distante de um padrão de reprodução de grandes famílias de juristas. Entre as indicações, nesse sentido, a análise dos sobrenomes dos principais sócios das 100 maiores sociedades aponta apenas cinco como nitidamente administradas por herdeiros.

\section{MINISTROS DO STJ E STF E A JUSTIÇA DE ESTADO}

Entre os três segmentos da elite jurídica analisados, os ministros do STF e STJ tomados como representativos da cúpula do Judiciário são os que mobilizam menos capital internacional nas suas trajetórias. Os dados dos percursos universitários e profissionais indicam que o recurso ao espaço internacional não se apresenta fundamental para a hierarquização das carreiras destes "juristas de Estado". Em contrapartida, ocorre a predominância da acumulação de trunfos vinculados ao espaço doméstico centrados na ocupação de postos no setor público, combinada com a inserção acadêmica nacional.

Os casos que apresentam inserção internacional por titulação acadêmica no exterior ou por integrar redes internacionais temáticas, tais como os "juízes pela democracia"12, invariavelmente têm uma carreira acadêmica paralela e complementar aos postos ocupados no Estado. Se compararmos os caminhos profissionais e os meios mobilizados pelos agentes posicionados na cúpula do Judiciário brasileiro, teremos que o peso de inserção em redes regionais - como direção de associações de juízes, combinada com uma longa carreira de magistrado ou procurador - tem peso predominante em relação à mobilização de qualquer espécie de capital internacional.

A análise dos perfis de formação acadêmica de 10 ministros do STF atuando em $2007^{13}$ indica que apenas três realizaram algum tipo de formação no exterior. No mesmo sentido, encontra-se o domínio de idiomas: dos 10 casos analisados, somente metade declaram ter fluência em algum idioma estrangeiro. No caso do STJ, entre 33 ministros, nenhum realizou estudos no estrangeiro. Mesmo os ministros do STJ que possuem maior inserção internacional não parecem constituir um capital internacional relevante que repercuta no conjunto das suas trajetórias de ascensão à cúpula judicial, tampouco em uma carreira acadêmica paralela a suas atividades jurisdicionais. 
Globalização e Poder de Estado: Circulação Internacional de Elites e Hierarquias...

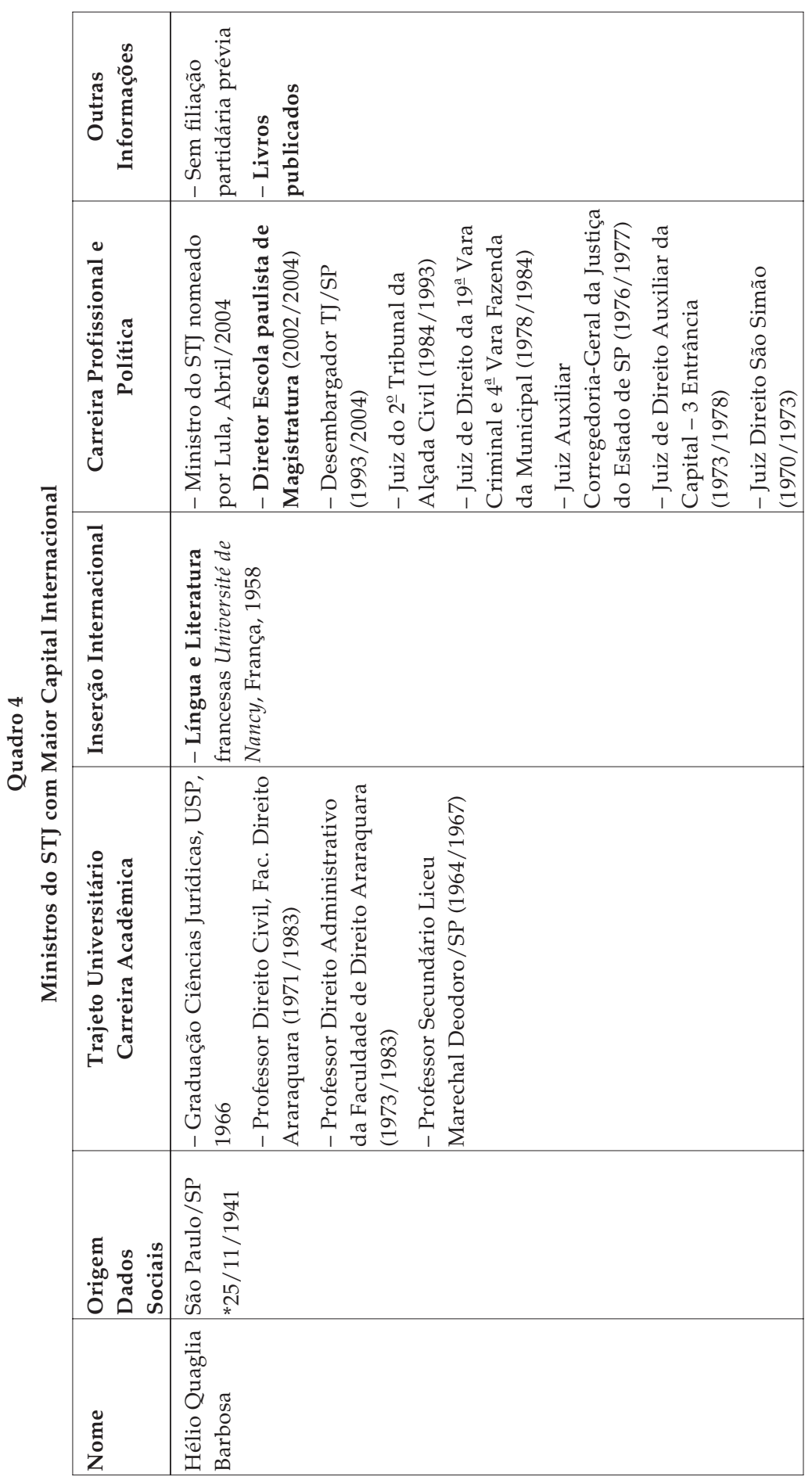


Fabiano Engelmann

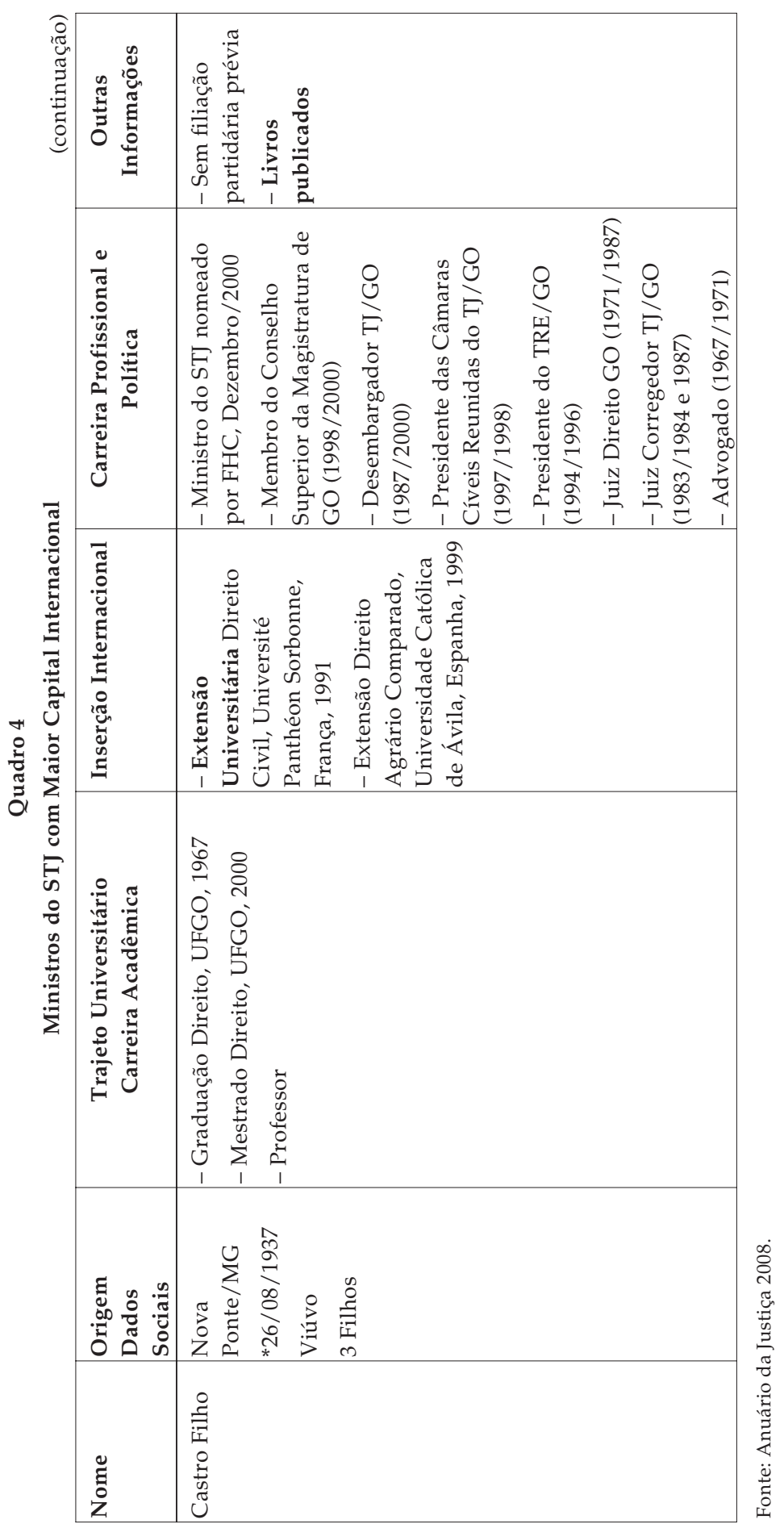


No STF, os três ministros que realizaram estudos no exterior o fizeram em três países diferentes: Estados Unidos, França e Alemanha. Das informações biográficas apresentadas no Anuário da Justiça 2008, pode-se destacar a "publicação de livros", evidenciando a importância do investimento em produção intelectual como componente da construção da posição de "grande jurista", que contribui para a ascensão aoSTF.

Em significativo número de trajetórias, aparece o pertencimento a diversas espécies de conselhos e diretorias de associações - penitenciário, Ordem dos Advogados do Brasil (OAB), Instituto dos Advogados Brasileiros (IAB) e diretoria de associações estaduais e nacional de magistrados -, combinado com a ocupação de postos de chefia de departamentos jurídicos e assessorias em organismos do poder Executivo. Essa forma de ocupação de postos evidencia a importância de um capital político imbricado à carreira jurídica e distinto da ocupação de mandatos parlamentares e dos exercícios de cargos eletivos.

A passagem predominante por departamentos jurídicos preenchidos por indicações políticas nos três poderes denota também a relação entre a expertise jurídica afinada com um caráter de "saber de Estado", garantindo historicamente posições para os juristas no âmbito do poder político, mesmo em um contexto de crescente concorrência com outras especialidades, como a economia, a gestão pública e, ainda, a ciência política $^{14}$.

O início da carreira dos ministros do STF ocorre majoritariamente através do cargo de magistrado, promotor ou advogado em escala estadual. Este padrão favorece maior investimento em redes de cunho localista $^{15}$. As exceções são os que iniciam em cargos de grande projeção e abrangência, como o de Procurador da República. Os ministros do STJ seguem um percurso semelhante aos do STF, com uma tendência a maior endogeneização ao campo da magistratura, tendo em vista que dois terços dos ministros do STF são recrutados entre magistrados de segundo grau, da justiça federal e dos tribunais estaduais, respectivamente. Tal regra não existe para o STF, onde o presidente da República escolhe os ministros que passam pelo aval do Senado.

Os ministros do STF que possuem maior capital internacional têm um perfil de carreira menos localista, além de manterem carreira acadêmica paralela às atividades jurisdicionais, conforme ilustra o quadro abaixo. 
Fabiano Engelmann

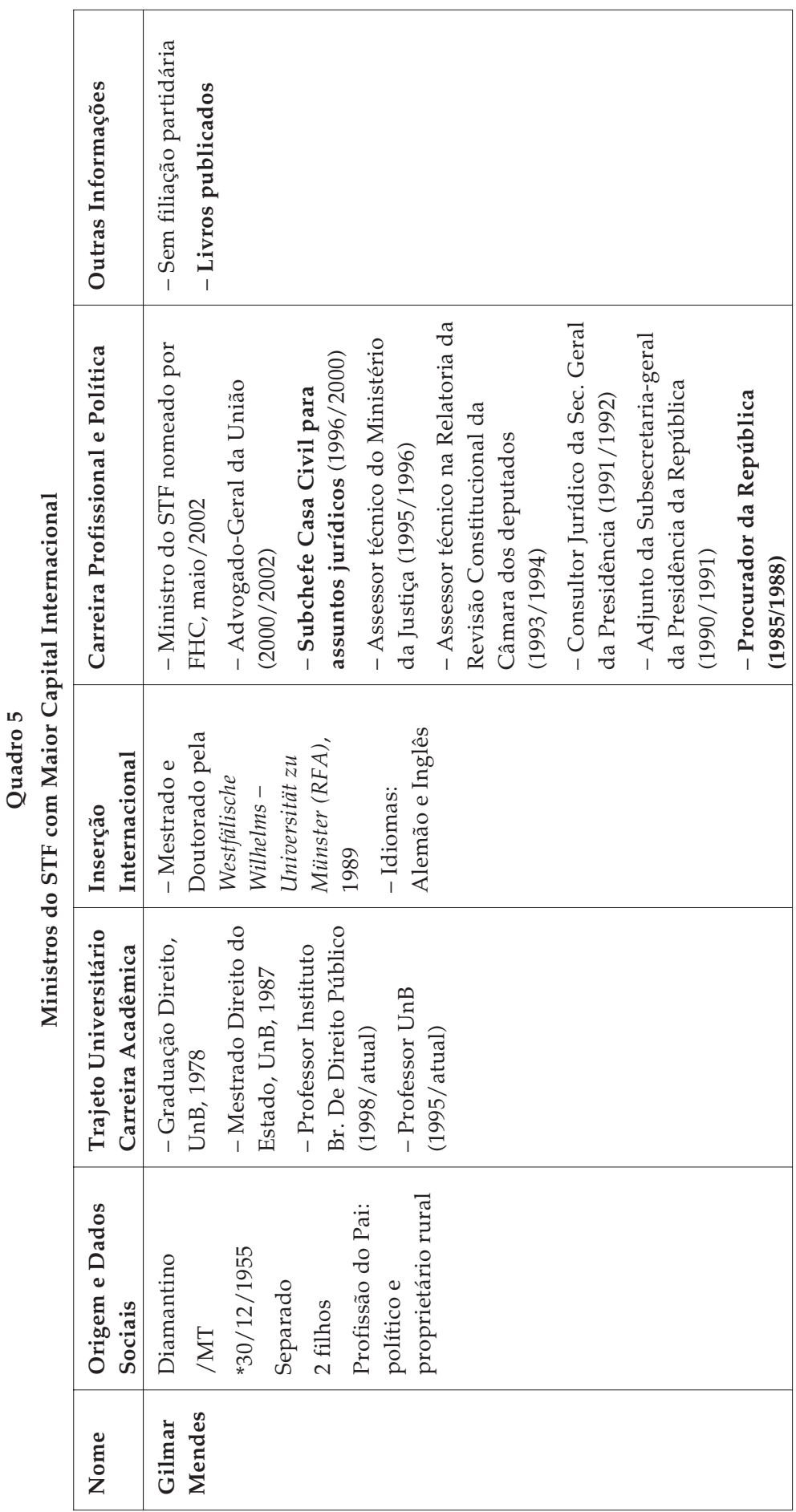

ฮ્త్ర 
Globalização e Poder de Estado: Circulação Internacional de Elites e Hierarquias...

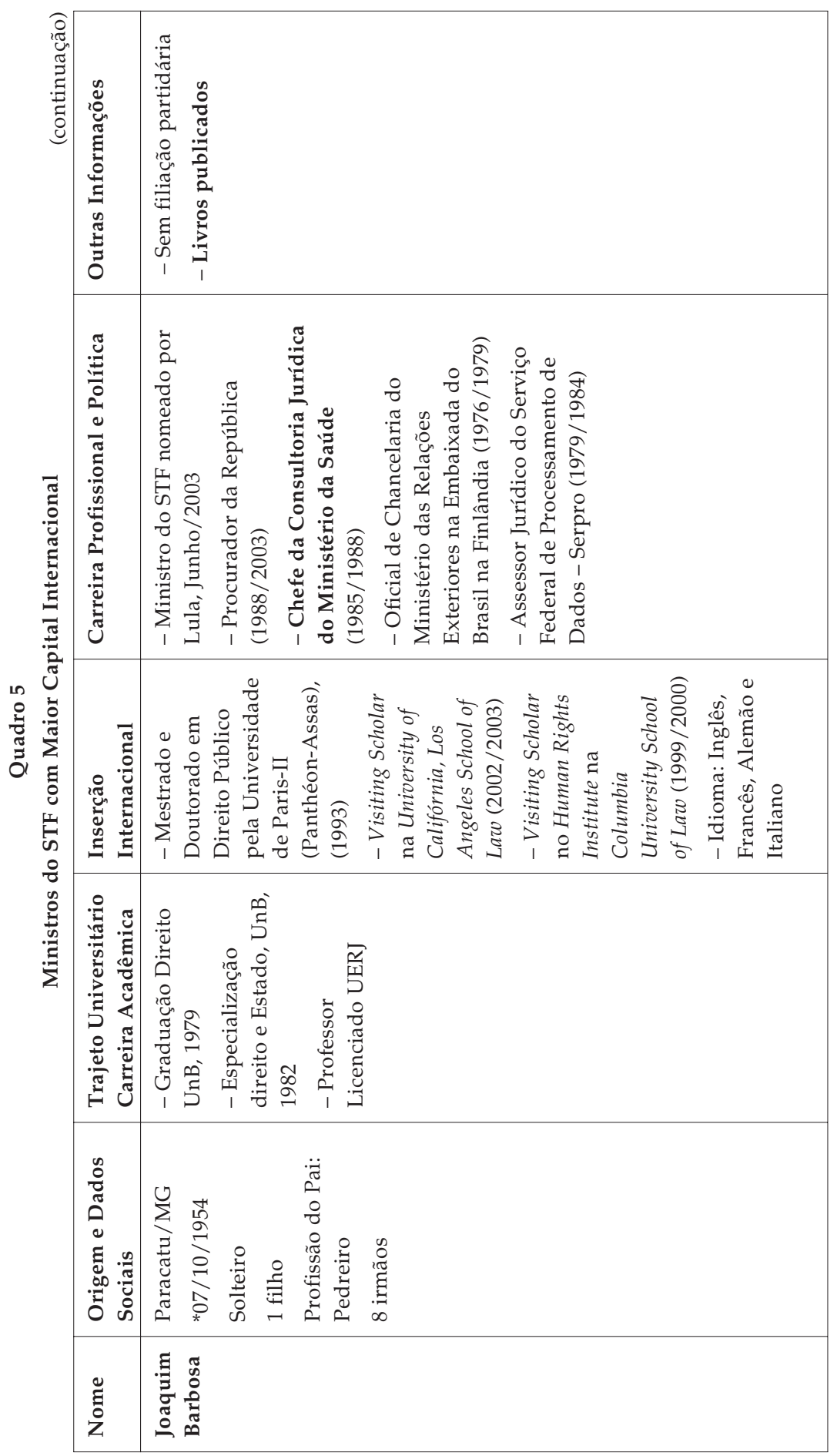


A repercussão pública das tomadas de posição política dos ministros Gilmar Mendes e Joaquim Barbosa ao longo da década de 2000 é indicativa da importância desses agentes no STF. Embora não se possa afirmar, com base nos dados disponíveis, que a formação acadêmica internacionalizada de ambos tenha sido determinante na ascensão à cúpula do Judiciário, seria interessante considerar essa dimensão na análise da construção de seus posicionamentos políticos através do estudo dos conteúdos de suas decisões judiciais.

\section{CONSIDERAÇÕES FINAIS}

A dificuldade de apreender as diversas bases da relação entre a produção do conhecimento sobre as instituições e a legitimação de grupos sociais no espaço de poder político amplia-se com a diversificação e a expansão da produção acadêmica e dos grupos que concorrem pelo sentido das instituições. A disseminação das redes de intercâmbio universitário e a circulação dos grupos dirigentes entre centros produtores e centros predominantemente importadores de conhecimento científico tornam mais complexa a tarefa de relacionar esses conjuntos de conhecimentos com os espaços e instituições que seus porta-vozes constroem ou remodelam em contextos específicos.

Um dos desafios postos aos estudos que partem das ciências sociais sobre as instituições é dar conta da complexificação deste campo de poder, formado, de um lado, por espaços crescentemente diversificados de expertises, e de outro, pela competição entre as elites que detêm variadas formas de poder político derivado do conhecimento técnico.

Com um ponto de partida próximo em seus estudos universitários (majoritariamente em universidades federais ou estaduais centrais, nos casos de São Paulo e Rio de Janeiro), os três segmentos da elite judicial que foram analisados dividem-se em seus percursos em diferentes modalidades de investimentos a partir do início da carreira profissional.

Evidentemente que uma apreensão detalhada desses diversos caminhos envolve também considerar as disposições adquiridas a partir das origens e trajetórias até o ingresso na Universidade, como a procedência e as espécies de capitais derivados do grupo familiar ou as disposições para atuar no setor público ou privado. O mesmo ocorre no caso dos professores universitários, carreira ainda recente no meio dos juristas. Nesta encontra-se uma relação forte entre a ascensão social e o 
investimento em titulação, muitas vezes combinada com a ocupação de um posto no setor público (Engelmann, 2006).

Este perfil de investimento insere profissionais do Direito voltados para a carreira acadêmica em um processo de profissionalização como docente, presente cada vez mais em outros domínios das "ciências sociais aplicadas".

Investimentos bastante distintos realizam os advogados de negócios, na medida em que a inserção no mercado de trabalho se dá ainda como estagiários de escritórios, e a familiaridade com o saber-fazer do mundo dos negócios afasta o direcionamento para longos cursos de doutorado no exterior ou no Brasil. Os cursos realizados no estrangeiro, invariavelmente, são curtos e financiados pelas sociedades de advogados nas quais esses bacharéis estão pré-inseridos. O capital internacional é formado mais por redes de contatos que afirmam a posição de representante judicial de multinacionais e menos pela acumulação de um capital internacional propriamente acadêmico.

O caso dos ministros do STF e STJ apresenta um padrão de longo percurso vinculado a carreiras no interior de diversas esferas estatais. A aprovação em um concurso público ou o início da prática de advogado em escala local denotam a importância do acúmulo de recursos derivados da experiência da prática judicial tradicional. Os deslocamentos para cidades do interior e as exigências para a construção da imagem de "bom juiz", assim como a ocupação de postos em associações, direção de foros ou cargos na burocracia judiciária, inevitavelmente dificultam os investimentos em uma carreira acadêmica internacionalizada. Nesses casos, a acumulação de capital internacional tem um custo desproporcional aos resultados que outras espécies de recursos mobilizados na ascensão mais rápida à cúpula do Judiciário.

As conclusões presentes na análise dos trajetos internacionais desses três segmentos, tomados como amostras da elite jurídica brasileira, fornecem indicações da complexidade do estudo da relação entre o capital internacional e a hierarquização de espaços de poder. Evidenciam as diferentes formas em que este capital internacional pode aparecer e ser mobilizado nas distintas frações da elite jurídica; seja certificado em títulos acadêmicos - como tende a predominar entre os segmentos que investem no ensino de pós-graduação -, seja na forma de um capital de contatos comerciais e profissionais presente na esfera dos advogados de negócios. 
A melhor compreensão do significado desta complexa relação entre internacionalização do espaço de expertises sobre o Estado com a construção da legitimidade doméstica de determinados grupos passa pela necessidade de um estudo fino dos diversos campos de poder, em que a "técnica" das elites se confunde com os diversos modelos de relações políticas.

(Recebido para publicação em maio de 2010)

(Reapresentado em setembro de 2011)

(Aprovado para publicação em maio de 2012) 


\section{NOTAS}

1. Para uma discussão dos caminhos de análise desses estudos, ver Dezalay e Garth (2002) e Popeau (2004).

2. A análise de Dezalay (2001) retrata a disputa entre a tradição jurídica de gestão do Estado e a cosmovisão econômica a partir do efeito de internacionalização dos saberes do Estado e exportação das disputas internas ao espaço de poder americano.

3. Para um panorama sobre a atuação dos think thanks, perfil de consultores que circulam no mundo das fundações privadas e como conselheiros de governantes, ver Boucher e Royo (2006).

4. Para um panorama desses trabalhos, ver Almeida et alii (2004) Santamaria e Vecchioli (2008).

5. Indicações sobre a configuração do espaço dos juristas no Império em especial sua participação na conformação dos modelos de instituições política podem ser encontradas em Adorno (1988), Carvalho (1996) e Koerner (1998).

6. Para um panorama da configuração dos cursos jurídicos no Brasil, ver Rodrigues (1992) e Engelmann (2006)

7. Ver para o campo dos advogados, Dezalay e Garth (2002), Bonelli et alii (2007).

8. Para maiores detalhes sobre as condições de profissionalização do ensino jurídico no Brasil a partir da década de 90, ver Engelmann (2006).

9. Para um panorama dos recursos e expertises mobilizados pelos economistas para a ocupação de espaços no estado, ver Loureiro (1997).

10. Para o caso dos padrões de formação e a expansão das faculdades de Administração, ver Vasconcellos (1998) e para o ensino de pós-graduação nesta disciplina, ver Engelmann (2008).

11. Os dados foram retirados das informações contidas no ranking Análise-Advocacia-2007: os mais admirados do Direito, que contém informações para as 474 maiores firmas de advocacia do país.

12. Magistrados que integram a Associação dos Juízes pela Democracia, associação com sede em São Paulo e que mantêm intercâmbio com associações similares na Europa. Para maior detalhamento sobre o ativismo da AJD, ver Targa (2010).

13. OSTF é composto por 11 ministros. Durante o período da pesquisa há uma vaga em aberto. As informações sobre o perfil dos ministros do STF e do STJ foram obtidas no Anuário da Justiça, 2008 e na publicação Análise Justiça, 2007.

14. Nesse sentido ver o trabalho de Dezalay e Garth (2000) e (2002) e a análise das oposições entre os "político-bacharéis" e os "técnico-políticos".

15. Um comparativo por distintos períodos históricos dos padrões de carreira dos ministros do STF pode ser encontrado no trabalho de Da Ros e Marenco (2007). 


\section{REFERÊNCIAS BIBLIOGRÁFICAS}

ABEL, Richard. (1998), "Speaking Law to Power: Occasions for Cause Lawyering", in A. Sarat e S. Scheingold (eds.), Cause Lawyering: Political Commitments and Professional Responsabilities. New York, Oxford University Press.

ALMEIDA, Ana M. et alii. (2004), Circulação Internacional e Formação Intelectual das Elites Brasileiras. Campinas, Editora da Unicamp.

ADORNO, Sergio. (1988), Os Aprendizes do Poder: O Bacharelismo Liberal na Política Brasileira. Rio de Janeiro, Paz e Terra.

BADIE, Bertrand e HERMET, Guy. (1990), Política Comparada. México, FCE. (1992), L'État Importe: L'Occidentalisation de l'Ordre Politique. Paris, Fayard.

BONELLI, Maria da Glória. (2002), Profissionalismo e Política no Mundo do Direito. São Carlos, EdUFSCar.

et alii. (2007), "Sociedades de Advogados e Tendências Profissionais". Revista Direito $G V$, vol. 3, pp. 111-138.

BOUCHER, Stephen e ROYO, Martine. (2004), Les Think Tanks: Cerveaux de la Guerre des Idées. Paris, Félin.

BOURDIEU, Pierre. (1986), “La Force du Droit: Éléments pour une Sociologie du Champ Juridique". Actes de la Recherche en Sciences Sociales, nos 2/3, pp 2-114.

. (1989), La Noblesse d'État. Paris, Minuit.

CARVALHO, José Murilo de. (1996), A Construção da Ordem: A Elite Política Imperial. Rio de Janeiro, Relume Dumará.

DA ROS, Luciano e MARENCO, André. (2007), Caminhos que Levam a Corte. Trabalho apresentado no $31^{\circ}$ Encontro Anual da Anpocs, de 22-26 de outubro, Caxambu, MG.

DELPEUCH, Thierry.(2006) “La Cooperation Internationale au Prisme du Courant de Recherche 'Droit et Développement'”. Droit et Societé, no 62, pp. 89-104.

DEZALAY, Yves. (1992), Marchand du Droit: La Restructuration de l'Ordre Juridique International par les Multionationales du Droit.

- e GARTH, Bryant. (2000), “A Dolarização do Conhecimento Técnico e Profissional do Estado: Processos Transnacionais e Questões de Legitimação na Transformação do Estado (1960-2000)". Revista Brasileira de Ciências Sociais, vol. 15, no 43, pp. 12-25.

. (2002), The Internationalization of Palace Wars: Lawyers, Economists and the Contest to Transform Latin American States. Chicago, University of Chicago Press.

ENGELMANN, Fabiano. (2006), Sociologia do Campo Jurídico: Juristas e Usos do Direito. Porto Alegre, SAFE.

. (2008), “Internacionalização e Legitimação da Formação Acadêmica em Administração no Brasil nas Décadas de 90 e 2000". Revista Tomo, no 13, pp. 239-263.

FORJAZ, Maria Cecília Spina. (1997), "A Emergência da Ciência Política no Brasil”. Revista Brasileira de Ciências Sociais, vol. 12, no 35 .

GRÜN, Roberto. (2004), “O MBA como um Brevê de Internacionalização e de Modernidade Profissional entre Engenheiros", in A. M. Almeida et alii (orgs.), Circulação 
Internacional e Formação Intelectual das Elites Brasileiras. Campinas, Ed. da Unicamp, pp. 282-298.

KOERNER, Andrei. (1998), Judiciário e Cidadania na Constituição da República Brasileira. São Paulo, Hucitec.

LÓPEZ-RUIZ, Osvaldo Javier. (2007), Os Executivos das Transnacionais e o Espírito do Capitalismo. Rio de Janeiro, Azougue Editorial.

LOUREIRO, Maria Rita. (1997), Os Economistas no Governo: Gestão Econômica e Democracia. Rio de Janeiro, Ed. FGV.

.(2004-2005), "Circulation Internationale des Économistes Brésiliens". Cahiers du Brésil Contemporain, n. 57/58-59/60. pp. 151-175.

PILAR, Domingo e SIEDER, Rachel. (2001), Rule of Law in Latin America: The International Promotion of Judicial Reforms. London, Institute of Latin American Studies/University of London Press.

POPEAU, Franck. (2004), "Sur deux formes de capital international". Actes de la Recherche en Sciences Sociales, no 151-152, pp. 127-130.

RODRIGUES, Horácio W. (1992), A Crise do Ensino Jurídico de Graduação no Brasil Contemporâneo: Indo Além do Senso Comum. Tese de Doutorado em Direito, Universidade Federal de Santa Catarina. Florianópolis.

SANTAMARIA, Ângela e VECCHIOLI, Virgínia (org). (2008), Derechos humanos en America latina. Mundialización y Circulación Internacional del Conocimiento Experto Jurídico. Bogotá, Ed. Universidad Del Rosário.

TARGA, Leandro G. (2010), A Politização do Direito na Magistratura: Ativismo Jurídico Via Associativismo de Juízes, uma Análise da AJD e da Militância pelos Direitos Humanos. Dissertação de Mestrado, Programa de Pós-Graduação em Ciências Sociais, Universidade Federal de São Carlos.

VASCONCELLOS, Maria Drosila. (1998), “L'Internationalization des Écoles de Gestion au Brésil". Actes de la Recherche en Sciences Sociales, nos. 121-122, pp. 123-137.

VENÂNCIO FILHO, Alberto. (1977), Das Arcadas ao Bacharelismo: 150 Anos de Ensino Jurídico no Brasil. São Paulo, Perspectiva.

VIANNA, Luiz Werneck et alii. (1999), A Judicialização da Política e das Relações Sociais no Brasil. Rio de Janeiro, Ed. Revan. 


\section{ABSTRACT \\ Globalization and State Power: International Circulation of Elites and Hierarchies in the Brazilian Legal Field}

Based on the issue of globalization of state expertise, the article intends to analyze the conditions in the internationalization of the Brazilian legal field, with a focus on the relationship between the international capital mobilized by jurists and the field's hierarchical structuring. The basis for the analysis consists mainly of the comparison between the university, professional, and political backgrounds of the three representative segments of the legal elite: faculty members in the graduate studies programs in law, partners in the leading law firms, and justices of the Superior Court of Justice and the Supreme Court. The various links to the international sphere can be related to the different positions in the Brazilian legal field and their relationship to the political and economic sphere.

Key words: legal elites; internationalization; state power

\section{RÉSUMÉ}

Mondialisation et Pouvoir d'État: Circulation Internationale des Élites et Hiérarchies du Champ Juridique Brésilien

Prenant comme point de départ la problématique de la mondialisation des travaux d'experts concernant l'État, on examine les conditions d'internationalisation du champ juridique brésilien visant surtout le rapport entre le capital international mobilisé par les juristes et la hiérarchisation dans ce champ. Cette analyse part surtout de la comparaison des trajectoires universitaires, professionnelles et politiques de trois segments représentatifs de l'élite juridique: enseignants dans les cours de doctorat en droit, avocats associés aux plus importants cabinets juridiques et ministres du Supérieur Tribunal de Justice et du Supérieur Tribunal Fédéral. Les divers liens avec l'espace international peuvent être rapportés aux différentes positions dans le champ juridique brésilien et à leur relation avec l'espace politique et économique.

Mots-clés: élites juridiques; internationalisation; pouvoir d'État 